\title{
AMAUROSIS AFTER OCCLUSION OF INTERNAL CAROTID ARTERY, TREATED BY CYCLODIATHERMY*
}

\author{
BY \\ CLEMENT MCCULLOCH \\ From the Department of Ophthalmology, University of Toronto
}

AMAUROSIs after occlusion of the internal carotid artery is a recognized clinical entity (Murphey and Miller, 1959). The present case is of interest because of the forms of treatment which were used and because of the discussion which their success suggests.

\section{Case Report}

A 50-year-old-man was hit on the right side of the head by a pot of paint on August 6, 1958. He was not knocked unconscious, although he was slightly dazed for a few minutes. On August 7 the vision became blurred, and he was unsteady on his left leg and clumsy with his left arm. On August 9 he talked as with a thick tongue and had difficulty in swallowing and his mouth tended to fill with saliva which he could not easily clear. Electro-encephalography on August 13 showed a focal, slow, electrical activity over the right fronto-temporal region.

During the next month the patient noted short periods of blurred vision in the right eye. These would last for a few minutes to several hours and then clear.

On September 9 the visual acuity was $6 / 9$ in the right eye and $6 / 6$ in the left. There was slight concentric constriction of the visual fields of the right eye for $1 / 1000,2 / 1000$ and $5 / 1000$ white test objects. The fields of the left eye were normal. The ocular tension of the right eye was $6.2 \mathrm{~mm}$. $\mathrm{Hg}$ and of the left eye $13 \mathrm{~mm}$. $\mathrm{Hg}$. Ophthalmodynamometry showed that the retinal arterial pressure was $10 / 30 \mathrm{~mm}$. $\mathrm{Hg}$ in the right eye and $35 / 90 \mathrm{~mm}$. $\mathrm{Hg}$ in the left.

The external structures of the eye, muscle balance, corneal sensation, pupils, media, fundi, and discs were all normal. Blood pressure in the right and left arms was 135/80 $\mathrm{mm}$. Hg. The right carotid arteriogram was reported as follows:

"The internal carotid is visible for not more than $1 \mathrm{~cm}$. from the bifurcation, at which point an apparent obstruction is met. The distal end of the dye appears rounded, not tapered. ... The dye passes freely through the external carotid artery and its branches ... . the intracranial part of the internal carotid artery and the middle cerebral artery are filled, apparently from anastomotic vessels."

The findings on electro-encephalography were similar to those of August 13. An anticoagulant, phenylindanedione, was given to keep the prothrombin time in the region of 30 seconds.

While using phenylindanedione the visual acuity of the right eye continued to fluctuate, varying from hour to hour. Readings between hand movements at 1 foot and 20/50

* Received for publication August 4, 1959. 
were recorded. On November 8 the ocular tension was $26 \mathrm{~mm}$. $\mathrm{Hg}$ in the right eye and $22 \mathrm{~mm}$. Hg in the left. The veins in the region of the right disc were slightly dilated.

Tolazoline, $50 \mathrm{mg}$. every 6 hours, was given, and the visual acuity of the right eye improved for a few days and then returned to its previous level of 20/50 or less.

On November 18 a right carotid arteriogram confirmed the previous findings. On November 21 the region of the right carotid artery was explored. The bifurcation was enveloped in dense scar tissue. The occlusion of the internal carotid artery we felt as a firm mass $2 \mathrm{~cm}$. above the bifurcation; beyond this the internal carotid artery felt soft. The artery was opened and a thrombus was removed. Above the thrombus the artery was patent to the skull but there was no retrograde flow of blood. It was assumed that the artery was blocked in the region of the foramen lacerum. No further attempt was made to open a passage and the artery and wound were closed. The pathological description of the thrombus was: "a laminated thrombus with an older, hyalinized, organized portion".

On November 26 there was a further decrease in vision of the right eye which grew gradually worse in the course of the day. On November 28 the visual acuity was hand movements at 3 feet in the right eye and 20/20 in the left. The ocular tension was 27.2 $\mathrm{mm}$. $\mathrm{Hg}$ in the right eye and $16.5 \mathrm{~mm}$. $\mathrm{Hg}$ in the left. Gonioscopic examination showed that the angles of both anterior chambers were open, the coefficient of aqueous outflow being 0.06 in the right eye and 0.20 in the left. Acetazoleamide $250 \mathrm{mg}$. was given three times a day.

During November 29 and 30 the visual acuity of the right eye improved to 20/100, fluctuating somewhat from hour to hour. On December 2 a cyclodiathermy procedure was done, three punctures being made in each quadrant between the recti muscles $4 \mathrm{~mm}$. behind the limbus, as has been described by Locke (1958).

Since this operation the ocular tension in the right eye has remained in the region of $9 \mathrm{~mm}$., and visual acuity has improved to about $20 / 50$, where it stays with little variation. The patient has been well, there is slight clumsiness of the limbs on the right side of the body, and a slight change in his speech, but he has returned to work. The visual field is reduced to $30^{\circ}$ with a $5 / 1000$ white test object. The retinal arterial pressure in the right eye continues to be low. The left eye remains normal.

\section{Discussion}

When considering treatment it was assumed that the amaurosis was due to insufficient circulation to the retina resulting from the occlusion of the internal carotid artery. At the capillaries of the retina two factors may be involved, insufficient flow of blood and insufficient capillary pressure. This second factor is particularly interesting. Insufficient capillary pressure may be considered as a decrease in the ratio between capillary pressure and retinal tissue pressure. The low-grade glaucoma which was present accentuated this decrease. When it was found impossible to raise the capillary pressure by opening the internal carotid artery, the alternative was to lower the intra-ocular pressure. The improvement in vision with the use of acetazoleamide indicated that a permanent procedure to lower the ocular tension would be worthwhile. The successful outcome of the ocular surgical procedure suggests that the nourishment of the retina does depend on a satisfactory balance between the pressure in the retinal capillaries and intraocular pressure. 
It is possible that in glaucoma the situation is not dissimilar. The rise in intra-ocular pressure leads to an unfavourable balance of pressure across the retinal capillary walls with resulting damage to the retina. Any vascular disease which lowers capillary pressure accentuates this unfavourable balance. Glaucoma may be a disease in which these two factors, an increase in ocular tension and a decrease in retinal capillary pressure, vary in importance from case to case.

\section{Summary}

Amaurosis after occlusion of the internal carotid artery was successfully treated by lowering the ocular tension. It is suggested that the balance between the retinal capillary pressure and the intra-ocular pressure is important in maintaining the integrity of the retina.

\section{REFERENCES}

MurPhey, F. and Miller, J. H. (1959). J. Neurosurg., 16, 1. LOCKE, J. C. (1958). Trans. Canad. ophthal. Soc., 10, 63. 